\title{
RUMO A UMA PEDAGOGIA COLONIAL NO/DO SUL GLOBAL ${ }^{1}$
}

\author{
Towards a Decolonial Pedagogy In/From the Global South
}

\author{
Alexander ORTIZ OCAÑA \\ Universidade de Magdalena \\ alexanderortiz2009@gmail.com \\ http://orcid.org/0000-0001-5594-9422 \\ María Isabel ARÍAS LÓPEZ \\ Universidade de Pamplona a distância \\ mariaisarias2015@gmail.com \\ Zaira Esther PEDROZO CONEDO \\ Instituição Educativa Thelma Rosa Arévalo \\ zairapedrozoc@gmail.com \\ Tradução de: Clayton FIORI \\ Universidade Federal do Paraná \\ fioriclayton@gmail.com \\ https://orcid.org/0000-0002-3023-8533
}

\begin{abstract}
RESUMO: O presente artigo discute as relações interpessoais que se desenvolvem no espaço de sala de aula entre professores e alunos, considerando a importância dos conteúdos curriculares nessa interação. É necessário que os professores reconheçam a pluralidade e a diversidade das formas de viver, estar, ser, pensar dos alunos, de modo a não incorrer em ações excludentes fundamentadas na colonialidade. Decolonizar a educação significa, entre outras coisas, reconhecer que os indígenas, camponeses, afro ou surdos, chegam à universidade não apenas para aprender, mas também para ensinar. A decolonialidade da educação é alcançada na mesma medida em que a validade e a importância dos "outros" conhecimentos não formalizados pela matriz colonial são reconhecidas. Finalmente, se queremos implantar a biopráxis pedagógica decolonial, devemos fazê-lo com a intenção de configurar o pensamento decolonial, lembrando que as pedagogias decoloniais exigem que os professores desenvolvam o pensamento a partir das margens e da fronteira. PALAVRAS- CHAVE: decolonial; educação; pedagogia; pensamento; práxis
\end{abstract}

\footnotetext{
${ }^{1}$ Publicação original: ORTIZ OCAÑA, A.; ARIAS LÓPEZ, M.I,; PEDROZO CONEDO, Z. E. "Hacia una pedagogía decolonial en/desde el sur global". Revista nuestrAmérica. Vol. 6, n.12; jul-dez 2018. pp. 195-222.
} 


\begin{abstract}
The interpersonal relationships that develop in the classroom space between teachers and students, in which the curricular contents have an extraordinary importance. It is necessary that teachers recognize the plurality and diversity of ways of living, being, being, thinking of our students, so as not to incur in these exclusionary actions in which coloniality underlies some of its dimensions. Decolonizing education means, among others arguments, reconizing that the indigenous, peasants, Afro or deaf, come to the university not only to learn and transform but also to teach. The decoloniality of education is achieved to the same extent that the validity and importance of the "other" knowledge not formalized by the colonial matrix is recognized. Finally, if we want to deploy decolonial pedagogical biopraxis, we must do so with the intention of configuring decolonial thinking and, in turn, these decolonial pedagogies require teachers to develop our thinking from the edges and the border.
\end{abstract} KEY WORDS: decolonial; education; pedagogy; praxis; thinking

\title{
1. PEDAGOGIAS "OUTRAS"
}

Já não é possível hoje em dia fazer reflexões sobre a pedagogia sem fazer referência às práticas educativas ou formativas, isto é, às relações interpessoais que se desenvolvem no espaço de sala de aula - ou fora dele - entre professores e estudantes, nas quais os conteúdos curriculares assumem uma importância considerável. É inútil que um professor profira um excelente discurso sobre a inclusão se se relaciona com seus estudantes a partir de sua etnia, estrato social, orientação sexual, crença religiosa ou ideologia política. Em algumas ocasiões, vemos professores formadores de docentes desenvolvendo um discurso sobre o construtivismo pedagógico e sobre o enfoque histórico-cultural, falando eloquentemente da teoria piagetiana e das inestimáveis contribuições de Vigotsky e, no entanto, este docente não permite que seus alunos perguntem e somente ele é quem fala, dando uma aula magistral, expositiva, sustentada em modelos pedagógicos tradicionais e em enfoques condutivistas. É possível também observar docentes planejando aulas sobre democracia e impondo seus critérios sobre o pensar e o sentir de seus estudantes. É preciso que os professores reconheçam a pluralidade e a diversidade das formas de viver, estar, ser e pensar dos estudantes, para não incorrer em ações excludentes nas quais subjaz a colonialidade em alguma de suas dimensões.

A educação é a estratégia de colonialidade por antonomásia, de tal modo que é através dela que se continua consolidando - e, às vezes, com a melhor das intenções, como é o caso das campanhas intensivas de alfabetização - o funcionamento da matriz colonial na formação dos 
imaginários, entendendo-os como as formas de perceber e compreender o mundo próprias de cada cultura, sempre conflituosas e contraditórias (PALERMO, 2014, p. 45).

A pedagogia por excelência para atenuar o exposto anteriormente é o exemplo cotidiano dos professores, seu comportamento ético, humilde, solidário e respeitoso. Um professor que com seu discurso pedagógico expresse desprezo pela diversidade de seus estudantes ou os trate desrespeitosamente, não merece exercer esta nobre e digna profissão. Em algumas ocasiões, ouvimos expressões que maltratam e reprimem a pluralidade humana nas salas de aula. É inverossímil que em pleno século XXI ainda existam professores que constranjam, desvalorizem e intimidem ao estudante ativista de um movimento juvenil, ao não-branco, ao que pratica uma religião e/ou formas não normativas de sexualidade, ao indígena, à mulher e ao afrodescendente.

Em todos os casos apresentados anteriormente, o valor da pluralidade humana não está sendo reconhecido pelo docente, e, portanto, não poderíamos falar de uma educação intercultural. Também não há educação intercultural quando o Estado ou o governo impõem os conteúdos curriculares sem permitir que os professores realizem as devidas adaptações e contextualizações levando em conta as particularidades e singularidades de seus estudantes. Palermo (2015) considera que a base da interculturalidade é a descolonização ativa das práticas educacionais. Se as práticas pedagógicas não se decolonizam, não há uma verdadeira interculturalidade. O Estado deve dialogar com as instituições educacionais e as universidades e não impor conteúdos curriculares eurocêntricos.

Decolonizar a educação significa, entre outras coisas, reconhecer que os indígenas, camponeses, afrodescendentes ou surdos, vão à universidade não só para aprender, mas também para ensinar. A decolonialidade da educação se alcança na mesma medida em que se reconhece a validade e a importância dos saberes "outros" não oficializados pela matriz colonial.

Quase sempre naturalizamos os componentes curriculares e pensamos que são invariáveis e não modificáveis. Os conteúdos curriculares, estratégias pedagógicas e estilos de ensino muitas vezes são alheios a - e estão distantes de - muitos estudantes que provêm de outros contextos socioculturais, vivenciam outras realidades, representam outras histórias, têm subjetividades diferentes, que foram configuradas em itinerários não reconhecidos, negados ou invisibilizados pelo discurso do Estado (Palermo, 2015).

A regularidade que emerge destas reflexões sobre a necessidade de uma educação intercultural que respeite a pluralidade e a diversidade humanas é uma crítica mordaz ao eurocentrismo da educação latino-americana em todos os seus níveis, desde a 
primeira infância até a universidade. A solução não está relacionada à criação de novos currículos problematizadores nem à aplicação de estratégias didáticas lúdicas, como se promove muitas vezes. O tema é muito mais complexo. Urge que nos desatrelemos do eurocentrismo pedagógico, curricular e didático que está impregnado no sistema educacional. A educação moderna oculta em sua retórica a lógica colonial. A colonialidade pedagógica, curricular e didática, constitui a face oculta do discurso educacional que tem configurado a modernidade.

A pedagogia moderna/ocidental não consegue reconhecer nem visibilizar as diferenças entre os seres humanos porque sua intenção formativa é a de homogeneizar e estandardizar, e, então, trata-se de uma pedagogia colonizante. Frente à diversidade/à diferença/ao outro/ao distinto/ao heterogêneo, a resposta foi fazer com que tudo se pareça ao modelo europeu colonial (Palermo, 2014). Essa é uma pedagogia obsoleta, cujos postulados epistêmicos estão em crise, perderam o prazo de validade; e é por isso que os educadores devem assumir os preceitos do giro decolonial, somar-se à resistência e lutar pela consolidação de uma pedagogia "outra".

Agora, para pensar uma pedagogia "outra" - não outra pedagogia - é necessário problematizar, desafiar, afrontar, fazer frente abertamente e resistir às diversas colonialidades que limitam nossa existência cotidiana: a colonialidade do saber, do poder, do ser e do viver.

Walsh (2012a) considera que quando enfrentamos a colonialidade do saber estamos criando as condições para transcender o monismo científico. Desta maneira, criam-se as bases para um sistema educacional "outro", desde a educação na primeira infância até a educação superior, desde a escola até a universidade. Essa nova concepção educacional pode - e deve - problematizar e desafiar as orientações e as racionalidades ocidentais e EUA-euro-cêntricas da geopolítica dominante do conhecimento na atualidade, tentando pluralizar as epistemes configuradas, instauradas e impostas a partir do sistema-mundo moderno/colonial.

$\mathrm{Na}$ América Latina esta geopolítica se evidencia na imposição do eurocentrismo como única e/ou dominante ideologia, episteme, epistemologia e metodologia do conhecimento. Nesse sentido, urge provincializar a Europa. O conhecimento gerado pelos Estados Unidos e pela Europa é um conhecimento local que tem sido imposto ao resto do mundo (exterioridade) com pretensões de universalidade. Esse é um legado do imperialismo e do colonialismo presente nas instituições educacionais e nas universidades, que dão maior valor à produção intelectual dos EUA e da Europa, contribuindo para 
sua nociva universalização. Dessa maneira, o pensamento do $\mathrm{Sul}^{2}$ se configura como um "saber localizado" (Walsh, 2009). Essa colonialidade epistêmica e epistemológica tem operado de maneira silenciosa e bem sucedida não somente nos sistemas educacionais, mas também nas teorias pedagógicas, negando outras formas ancestrais, diversas, singulares e/ou emergentes de construção de conhecimento, simplesmente por não serem europeias, norte-americanas, brancas, patriarcais e/ou "científicas" (partindo da epistemologia cartesiana-newtoniana).

Esta racionalidade empírico-positivista separa o conhecimento do mundo, assumindo uma epistemologia dualista fragmentadora, na qual o objeto de estudo existe "fora" do sujeito e, portanto, o conhecimento é interno e o mundo é externo. Em contraposição a essa ideia, Walsh (2012a) assume e nos exorta a viver uma vida holística, integral, na qual o conhecer e o viver estão estreitamente relacionados. Esta lógica que chamaremos holístico-configuracional localiza o conhecer e o processo de conhecer em um caminho diferente ao pensar instrumental e individual que transita por uma racionalidade meio-fim. A lógica holística do conhecer transita em/a partir/por/para um pensamento configuracional (Ortiz e Salcedo, 2014).

Os pressupostos e postulados configurados a partir desta lógica configurativa não são fechados, rígidos e dogmáticos, senão abertos e flexíveis, envolvendo todos os sentidos e aptidões do ser humano no processo de conhecer, e não pondo limites ao pensar nem ao conhecer. Desta maneira, poderíamos afirmar que o "bom viver" não é só praxiológico, social e econômico, mas também epistêmico (Walsh, 2012a).

Desde a epistemologia configuracional (Ortiz 2013; 2015; 2016c) a visão sobre o universo, o cosmos, o mundo em que vivemos, nossa própria prática sociocultural e nossas experiências, vivências, compreensões e significações (biopráxis) não é uma visão fragmentadora, senão holística, integradora e relacional, na qual se integram em um entretecido harmônico e coerente diversas configurações compreensivas: biológicosocial; emoção-razão; espaço físico-consciência; genético-cultural; interno-externo; material-espiritual; mente-corpo; objetivo-subjetivo; ser humano-natureza; sujeitoobjeto; tangível-intangível, entre outras relações. Walsh (2009) propõe precisamente que analisemos esse entramado desde a complementaridade, correspondência, reciprocidade e relacionalidade, como princípios fundamentais da nossa cosmovisão.

O viver humano (Kawsay) configura estes quatro princípios na fruição do sentido profundo da vida, na experiência plena de viver, gerada a partir da coerente tensão

\footnotetext{
${ }^{2}$ Seja América Latina, África, Ásia ou de qualquer Sul do planeta Terra. 
das polaridades que emergem da convivência intercultural harmônica e respeitosa ${ }^{3}$. Deste modo, esses princípios se configuram nas relações humanas e naquelas entre humanos e natureza, que devem ser harmônicas, equilibradas, equitativas, dignas e solidárias. Também são visíveis nas interrelações e interconexões entre culturas, lógicas, racionalidades, saberes e seres (Walsh, 2012a). Sob este olhar relacional, o pensar, o agir e o viver constituem uma configuração triádica.

O exposto anteriormente nos leva a problematizar a episteme da razão universal, devemos questionar a ideia de uma verdade global, estabelecendo as bases para a configuração de outras racionalidades, de verdades "outras" que desafiem e enfrentem o caos ecológico (ambiental, espiritual, humano e social) no qual vivemos cotidianamente. Isto permite configurar novas formas de conviver em cidadania, diversidade e harmonia, que visibilizem as cosmovisões, epistemologias, filosofias, práticas e maneiras de viver ancestrais, que se sustentam em verdades e razões diferentes, bem como em maneiras "outras" de pensar, sentir, saber, agir e viver.

O bom viver enfrenta e rompe com a epistemologia moderna/ colonial, a partir da qual nos comunicam - e impõem - que o conhecimento nos permite alcançar o mundo. $\mathrm{O}$ bom viver nos convoca a assumir um outro olhar epistemológico, que tem sentido para a grande maioria dos seres humanos: o mundo nos permite acessar o conhecimento, portanto, não penso, logo existo; mais do que isso: penso de acordo onde vivo. O viver determina o pensar e não o contrário, como nos leva a enxergar a epistemologia eurocêntrica. Isso aponta para uma epistemologia, pedagogia e razão decoloniais (Walsh 2006b; 2008a).

Com isso, podemos afirmar que o que precisamos na educação latino-americana não é somente reestruturar (González 1998; Castro-Gómez 2000), indisciplinar (Walsh, Schiwy e Castro-Gómez 2002), reinventar/renovar (Santos 2006b), repensar/ abrir (Wallerstein 2010a; 2011) ou reconfigurar (Ortiz 2016c) as ciências sociais. O que precisamos é decolonizar as ciências sociais, ou seja, configurar ciências sociais “outras", decolonizar a eurociência e a europedagogia que nos têm colonizado já há mais de 400 anos, a partir do cogito ergo sum cartesiano, da Didática "Magna" de Comênio (2012), da Pedagogia "Geral" de Herbart (1806), e da concepção instrumental de Curriculum proposta por Bobbitt $(1924 ; 1941)$ e referendada em Tyler (1986).

Esta louvável e urgente tarefa de decolonizar a educação, as ciências sociais, a pedagogia, o currículo e a didática, não é possível somente a partir da teoria e da pedagogia críticas. A teoria crítica (Horkheimer, 1998), em sua formulação clássica da Escola de Frankfurt, e a pedagogia crítica em seus postulados epistêmicos originais, e

\footnotetext{
${ }^{3}$ http://www.amawtaywasi.edu.ec/objetivos.html

Revista X, v. 16, n. 1, p. 118-146, 2021.
} 
nas repercussões do que McLaren (1997a; 1997b; 1998) chama de pedagogia crítica "revolucionária", são propostas marxistas e antropocêntricas, esforços ocidentais que partem de um projeto, pensamento e pressupostos paradigmáticos modernos/coloniais, através dos quais fazem crítica eurocêntrica ao eurocentrismo.

Por outro lado, Grande (2008) afirma que a pedagogia crítica revolucionária está em tensão com a práxis indígena e o conhecimento, daí que continue enraizada no paradigma ocidental. É por esta razão que as configurações conceituais que permitem compreender a democratização, a propriedade e a subjetividade, estão definidas por configurações eurocêntricas que compreendem o ser humano como um sujeito primário de "direitos" e status social. (Grande, 2008). Por outro lado, nos Andes, Walsh (2014c) percebe que a mobilização, transformação, autodeterminação, descolonização e decolonialidade estão estreitamente enraizadas no conhecimento, cosmologia, cultura, espiritualidade, natureza, sabedoria, terra e vida; aspectos caracterológicos do projeto pensado em/por/a partir/ para os povos indígenas. Desta maneira, a colonialidade e a diferença colonial devem ser abordadas por pedagogias "outras".

Essas pedagogias "outras" não têm sido abordadas de maneira aberta, direta e profunda pela modernidade e pela teoria crítica; e também não estão presentes de maneira explícita nas obras de Freire (1987; 2011; 2012a; 2012b; 2013a; 2013b; 2014) nem em nenhuma das obras de Martí (1961; 1975; 2007). Walsh (2014c) tem se distanciado do pensamento crítico ocidental, da pedagogia crítica, e inclusive de Freire, procurando e percorrendo novos caminhos, diferentes trajetórias e atalhos, perguntando e caminhando. Nesta mesma ordem de ideias, Mignolo (2007b;2008a), partindo do pensamento decolonial, nos convida a assumir uma opção decolonial que nos aproxime do desprendimento e da abertura epistemológica. Desprender-nos das ciências da educação e abrir a Pedagogia implica deixar de caminhar pelas epistemes enraizadas na epistemologia moderna/ colonial e começar a configurar novos caminhos epistêmicos e epistemológicos nas margens de tais epistemes, caminhos fronteiriços por onde transitar decolonialmente. E concordamos com Walsh (2014c): nossos caminhos nos fizeram duvidar da teoria crítica do ocidente e nos induziram a suspeitar que não se vê a colonialidade como o lado obscuro da modernidade. Devemos repensar as ciências da educação. Temos a impressão de que aqueles que criticam a pedagogia tradicional ainda estão atrelados a ela. Nem nós mesmos estamos isentos de assumir em certas ocasiões seus postulados eurocêntricos colonizantes. Isso confirma o quão arraigados estão em nós os pressupostos epistêmicos que promulga e a urgência de se repensar a pedagogia. 
A partir do olhar esboçado anteriormente, consideramos que a pedagogia é uma "verbalidade" (Vázquez, 2012); não é um simples substantivo, senão um verbo; não é um ser (ontologia), mas um fazer (praxiologia). A pedagogia não se trata de uma simples disciplina ou fazer pedagógico, como considerava Zuluaga (1987; 2001; 2003; 2005). Walsh (2014c) não está interessada na pedagogia como uma disciplina. Ao contrário, valoriza seu sentido e significado nas ações, nas estratégias, nas formas de fazer, nas metodologias, nas práticas, que se configuram em/com afirmação, insurgência, reexistência e resistência, como base para imaginar, sonhar e configurar um mundo "outro" onde caibam muitos mundos "outros".

Como se vê, esta autora postula uma concepção diferente da Pedagogia; se compromete cada vez mais a uma busca mais ampla e profunda que requer pedagogizar o decolonial, e assume o pedagógico a partir de uma visão praxiológica, a pedagogia como práxis, seguindo os caminhos de Freire (2011; 2012a; 2013b; 2014). Segundo Walsh (2014a), as perspectivas e projetos de críticos decoloniais e interculturais devem estar entrelaçados a pedagogias ou perspectivas pedagógicas diversas. Pensamos que é o momento oportuno para a ação e o pensar decoloniais, se considerarmos as mudanças que a América Latina passa no início do século XXI:

- Aparecimento cada vez mais enérgico e dinâmico de intenções, projetos e processos sustentados em - e encaminhados à - decolonialidade.

- Insurgência, resistência e (re)existência epistêmica, epistemológica, política e social.

- Disseminação de movimentos e comunidades afrodescedentes, camponesas, femininas e LGBTI.

Esta autora não discute o processo de decolonizar a pedagogia como disciplina e ciência da educação, mas se concentra no processo de pedagogização das decolonialidades. Pensamos que, a partir do olhar dialético configurativo, ambas as formas são necessárias, urgentes e importantes: pedagogizar o decolonial e decolonizar a pedagogia, sobretudo porque esta disciplina, assim como demonstrado por Spivak (2015) a respeito da filosofia, da literatura, da história e da cultura ocidentais, está permeada por um passado colonialista que ainda não foi superado e se reconfigura em nosso presente pós-moderno/ colonial. É bem-vinda, assim, a proposta de Walsh (2014a), que nos convida a configurar "pedagogia(s) decolonial(ais)".

A partir desta perspectiva, o processo de pedagogizar a decolonialidade empregaria parte da terminologia eurocêntrica, que perpetua mais do mesmo. Em outras palavras, seria possível fazer um chamado às práticas, ao pensar decolonial partindo de um ponto 
de vista crítico que permita o pensar e o agir de outra maneira, já que pedagogizar o colonial não é o mesmo que decolonizar a pedagogia. Decolonizar a pedagogia fala de ações sobre o termo e sobre as construções ocidentalistas que temos de especificar a partir do nosso sentir e fazer, que nos permitirão ir abandonado conceitos e conteúdos que nos subalternizam. É urgente transitar na direção de uma pedagogia decolonial.

\section{PEDAGOGIA DECOLONIAL}

Segundo Palermo, não há "pedagogia" sem adjetivos, posto que "a pedagogia sem modificador é uma pedagogia oficial, a serviço do sistema político e econômico que a sustenta, promove e, também, a deixa cair em prol de medidas mais 'eficientes'" (PALERMO, 2014, p.9).

Por outro lado, Esmeral e González (2015) integram a Pedagogia e a Interculturalidade; oferecem critérios dialógicos das realidades socioeducacionais no Caribe colombiano. Entretanto, quando fazem referência ao currículo do retorno, tentam integrar emancipação e decolonialidade, porém sua análise é insuficiente, pois não se aprofundam na configuração epistêmica da decolonialidade e seu potencial epistemológico, libertador e emancipador. Portanto, é necessário e urgente ampliar e aprofundar o discurso da decolonialidade da educação como operação e ação epistêmica e epistemológica para desprender-nos do nocivo eurocentrismo instaurado pelo sistema-mundo capitalista/ moderno/colonial. Pensar a decolonialidade da educação torna-se assim a emergência/ urgência de uma pedagogia decolonial.

Walsh (2014a) não soma a pedagogia decolonial à pedagogia crítica, nem sugere o decolonial como manifestação contemporânea da pedagogia crítica. De fato, afirma que a genealogia da pedagogia decolonial pode ser encontrada na práxis emancipatória das comunidades afrodescendentes e dos povos indígenas, que têm exercido posturas libertadoras e configurado projetos políticos entendidos como pedagogias. Estas formas de pensar, sentir e agir integram e configuram a pedagogia e a interculturalidade, desde uma perspectiva decolonial, sem a necessidade de transitar previamente pelos postulados da teoria crítica.

\section{O quê - e como - são as pedagogias decoloniais?}

- Pedagogias que promovem práticas insurgentes de resistir, (re)existir e (re)viver (Walsh, 2017).

- Pedagogias que se sustentam nas lutas e práxis de orientação decolonial, mas que, ao mesmo tempo, consideram os antecedentes crítico-políticos. 
- Pedagogias que desafiam o monólogo da razão moderno/ocidental/colonial e o mito racista da modernidade/colonialidade (Bautista, 2009).

- Pedagogias quevisibilizama geopolítica do saber, a teleologiaidentitária-existencial da diferença colonial da diferença colonial e a topologia do ser (MaldonadoTorres, 2006a); processos negados ou ocultados pelo multiculturalismo.

- Pedagogias que configuram a análise crítica, o questionamento, a ação social transformadora, a insurgência e a intervenção nos campos do poder, saber, ser e viver; e, por último, fomentam e assumem uma atitude insurgente, isto é, decolonial.

- Pedagogias que transgridem, mudam e incidem na negação cosmogônicaespiritual, epistêmica e ontológica, que foi - e é - estratégia, fim e resultado do poder da colonialidade.

- Pedagogias que abrem brechas, desprendimentos e novos engajamentos.

- Pedagogias que provocam aprendizagens, desaprendizagens e reaprendizagens.

- Pedagogias que esclarecem e enredam caminhos; não cultivam dogmas, mas plantam sementes para que possam germinar conhecimentos “outros", igualmente válidos em relação aos saberes estabelecidos.

- Pedagogias que configuram diversas formas de agir, ouvir, estar, fazer, olhar, pensar, sentir, ser, teorizar, decolonialmente, não só de maneira individual, mas em/a partir/por/para o coletivo (Walsh, 2013), isto é, uma pedagogia da comunidade.

Partindo do exposto anteriormente, Walsh (2014a) considera que as pedagogias decoloniais devem configurar-se nas instituições educacionais, universidades, bairros, comunidades, lares, nas ruas, nos movimentos e organizações. As pedagogias decoloniais não são utopias (no sentido comumente atribuído a este conceito como algo irrealizável), senão utopísticas (no sentido proposto por Wallerstein, 2003). Esse autor considera a utopística a avaliação séria, realista e profunda das melhores alternativas, propostas criativas, originais, inovadoras e plausíveis. Ele a propõe como uma prática simultânea nos campos científico, moral e político. Precisamente neste âmbito se inserem as pedagogias decoloniais. Devemos encarar a utopística não a partir de uma perspectiva etimológica, mas sim desde o sentido amplo de seu significado e conteúdo. Essa noção constitui uma grande contribuição para esta montanha de neve que precisa de esquiadores que superem o medo ao novo, às mudanças, à crítica e à alienação da sociedade.

Todos os seres humanos que vivemos atualmente neste mundo convulso, neste imprevisível século XXI, agora mesmo, neste preciso momento, estamos moldados pelo 
discurso da modernidade/colonialidade em todas as suas dimensões: saber, poder, ser, viver. É necessário pensar partindo de um lugar "outro"; é imperativa a necessidade de se refletir a partir da exterioridade da episteme eurocêntrica (Palermo, 2014) para poder dar origem a uma pedagogia decolonial que faça frente ao pensamento único e universal. Mas como?

Lembremos que no oprimido se oculta também um opressor:

O grande problema reside em como poderão os oprimidos, como seres duais, inautênticos, que "abrigam" o opressor em si, participar da elaboração da pedagogia para a sua libertação. Somente na medida em que se descubram 'abrigando' o opressor poderão contribuir para a construção de sua pedagogia libertadora (FREIRE, 2012a, p. 42).

Só pode haver um distanciamento do opressor a partir da mente, em um contexto que leve em conta a vida cotidiana, fazendo do viver um paraíso de liberdades que o fazem ser tal e como é, e não como deveria ser, pensar e agir. Devemos sonhar, mas não de acordo com os sonhos alheios, senão como se vislumbra, se crê e se vê o mundo por outras fontes e pela natureza das coisas. Sob este olhar, as pedagogias decoloniais são sonhos que se delineiam nas biopráxis cotidianas dos seres humanos colonizados. As pedagogias decoloniais nunca são alcançadas totalmente, e os seres humanos subalternizados sempre lutaremos para alcançá-la; e nunca devemos abandonar nossa insurgência, resistência e re-existência nos âmbitos cultural, econômico, educacional, epistêmico, intelectual, político e social (Walsh, 2014a).

Ao continuar lutando por uma insurgência em todos os âmbitos, nos atreveríamos a pensar que a decolonialidade na educação em si se faz efetiva nesse mesmo processo de busca, de resistência à imponência, de rebeldia ante o que nos reprime, nos amarra e nos torna alheios de nós mesmos e de nossas origens. Ir mais além do prazer que outorga a modernidade, manifestando pensamentos "outros", nas vivências que marcam a essência pedagogizante.

Seguindo esta linha de pensamento, Da Silva (1999) enumera diversos discursos ou propostas educacionais que reformulamos adotando uma postura metacognitiva, na forma de perguntas. A partir desta perspectiva, se impõe a configuração de múltiplos discursos pedagógicos decolonizantes. Para que queremos educar? Educamos para doutrinar; assimilar; biculturalizar; compensar; diferenciar; empoderar; interagir (interculturalidade); reproduzir; tolerar ou prevenir o racismo e a exclusão; transformar (pedagogia crítica) ou decolonizar (antropo-decolonialidade)? Como educamos? 
Com estas reflexões, caminhamos em direção a uma pedagogia decolonial, tendo um olhar crítico, mas a partir de uma perspectiva decolonial, transitando rumo à decolonialidade global ou à globalização da decolonialidade. Sem cair na armadilha de centralizar os saberes, pensamentos e ações como vem fazendo a colonialidade. A cada dia nos convencemos mais sobre a necessidade de decolonizar nosso saber pedagógico, construir uma pedagogia decolonial, e transitar em nossas pesquisas sobre a educação na direção da decolonialidade epistêmica e da desobediência epistemológica. Levando em conta este olhar, apostar em uma pedagogia decolonial é caminhar para o desmonte da "pedagogia da crueldade", orientada a formar "sujeitos dóceis ao mercado e ao capital" (PALERMO, 2014, p.136).

É evidente que, hoje em dia, no campo da educação, é muito pertinente o discurso sobre a decolonialidade. Por exemplo, nas universidades reconhecidas não devemos trabalhar para o reconhecimento. Isso seria nos autocolonizar. O reconhecimento não é um fim, é um meio para alcançar outros fins mais transcendentais. O reconhecimento não é um fim, é um meio para alcançar outros fins. O reconhecimento não é resultado, mas um processo. E um resultado nunca faz parte do processo que o origina. Se olhamos só para o resultado e nos concentramos nele, então não vemos o processo, que é o mais importante. Não devemos trabalhar para o reconhecimento, devemos trabalhar para a decolonialidade da educação; e se conseguirmos, certamente receberemos o reconhecimento permanente. É preciso construir uma cultura da excelência, pertinência, sentido e decolonialidade do viver.

Illich (1974) propõe uma sociedade desescolarizada, com uma ironia aguda, na epígrafe intitulada Por que devemos privar as escolas de apoio institucional?, sugere que as escolas adestram os estudantes, ensinam-lhes a confundir o processo com a essência, e, desta maneira, constroem uma nova lógica que associa os resultados de qualquer processo ao tratamento dado a ele. As instituições educacionais são escolarizantes, a tal ponto que os estudantes confundem o saber com o ensino, a competência com o certificado, a formação com a aprovação para a série seguinte e a capacidade de comunicar com a fluência.

Neste ano de 2017, em quase todas as Universidades da Colômbia, um amplo, forte e profundo debate está sendo realizado sobre os resultados das provas Saber$\mathrm{Pro}^{4}$. Quase todas as universidades colombianas estão envolvidas na hercúlea e quase impossível tarefa de pensar e implementar estratégias para que os estudantes alcancem bons resultados nessas provas.

\footnotetext{
${ }^{4}$ Trata-se de provas aplicadas pelo Estado a todos os estudantes do país, em todos os níveis, com o objetivo de "medir" e "avaliar" a "qualidade da educação".

Revista X, v. 16, n. 1, p. 118-146, 2021. 
Ortiz(2017b) realizou algumas reflexões nas diversas reuniões metodológicas feitas para analisar o resultado das provas Saber-Pro 2016, na Faculdade de Ciências da Educação da Universidade de Magdalena (Santa Marta, Colômbia). A seguir, sistematizamos o que este autor denominou Decálogo para conseguir que nossos estudantes alcancem excelentes resultados nas provas estandardizadas, já que entendemos que esta proposta se insere na perspectiva decolonial da educação, da pedagogia, do currículo e da didática, mesmo que reconheçamos que não necessariamente têm de ser dez logos (decálogo). Poderiam ser sete ou onze; o mais importante não é o número, nem a quantidade de propostas senão as reflexões que estas podem suscitar:

a) Não nos compararmos com outras universidades, nem entre programas acadêmicos.

São seres humanos diferentes, portanto processos incomensuráveis. Uma universidade pode estar em primeiro lugar e não ter avançado. Outra universidade pode estar em último lugar e ter avançado.

b) Ignorar as provas, não pensar nelas, não as considerar. Que as provas não nos tirem o sono.

Quanto mais pensarmos e analisarmos os resultados das provas, menos possibilidades teremos de reverter esses resultados. Porque nos perdemos nos resultados. Nos perdemos nos números e não vemos o processo.

c) Não preparar os estudantes para as provas, mas para a vida.

As provas não são nem sequer parte dessa vida. Uma universidade pode ter o primeiro lugar nas provas e não estar formando boas pessoas, amorosas, responsáveis, respeitosas e solidárias. Isto a prova não mede.

d) Não pensar nos resultados; concentrar-nos somente no processo de formação.

Um resultado nunca é parte do processo que o originou. Se me foco no resultado, nunca vejo o processo. Devemos nos concentrar no processo, e o resultado é uma consequência desse processo. O resultado é derivado do processo, mas não faz parte dele.

e) Reconhecer que os resultados de qualquer processo avaliativo não dependem da pessoa avaliada, mas do avaliador e do instrumento avaliativo.

Se muda o instrumento também mudam os resultados. $O$ que aconteceria se na próxima prova o Ministério de Educação mudasse o estilo das perguntas?

f) Desenvolver de maneira constante e permanente em cada uma das aulas 4 ações formativas: ler, escrever, refletir e conversar.

Ler, escrever, refletir e conversar. Não há outra solução mais adequada e pertinente. Tudo o mais que façamos será paliativo, "panos de água quente”. 
Podemos desenvolver atividades com 25 ou 200 alunos. Essa não é a questão. A questão é que nas aulas não lemos, não escrevemos, não refletimos e não conversamos. E esta é a ontologia e a condição humana: ler, escrever, refletir e conversar.

Não há aprendizagem autêntica e profunda sem ler, escrever, refletir e conversar. Quantos livros leem nossos estudantes em cada disciplina por semestre acadêmico? Que autores leem? Quantas páginas escrevem sobre o que foi lido? Refletem em aula sobre o que foi lido e escrito? Conversam sobre um problema, tema ou questão relacionada à disciplina?

Estas quatro perguntas também se aplicam a nós, os professores. Quantos livros lemos num ano? Que autores lemos? Quantas páginas escrevemos por ano, e quantas publicamos? Como desenvolvemos nossa reflexão em aula? Conversamos com nossos estudantes em sala? Estimulamos e potencializamos a reflexão e o diálogo entre eles?

A leitura e a escrita são processos compartilhados, que requerem um fim determinado. Nesse sentido, nossos estudantes devem saber para que leem e o que fazem com o que leem; o que fazem com as leituras que os cursos de formação docente sugerem; por que leem isso e não outra coisa. Mas, sobretudo, a generalização: o que escrevem a partir do que leem; que reflexão emerge de tal leitura; e sobre o que conversam a partir de tal leitura.

A pergunta pela quantidade de livros que lemos em um ano não indica nem sugere que a aprendizagem depende da quantidade de livros lidos, nem deve ser uma camisa de força para que autores devem ser lidos ou não. Isto deve ser uma opção, tanto a quantidade quanto os autores. Não deve ser uma imposição; deve-se estabelecer um pensamento crítico a partir da fronteira, no momento de expressar os conhecimentos. Não obstante, a resposta a esta pergunta nada trivial revela, sim, o que estamos fazendo e o que não; e o que devemos fazer para aprender, sobretudo por meio de configurações e matizes decoloniais.

g) Os professores que dão uma mesma disciplina não devem imprimir uma mesma visão ao conteúdo curricular.

Se homogeneizamos o conteúdo, limitamos a aprendizagem. O estudante deve saber que existem diferentes perspectivas, percepções e concepções sobre uma mesma questão. Além disso, não há formação holística e desenvolvimento humano integral sem conflitos. A diversidade cognitiva configura contradições, que fazem parte do pensar e refletir. E isto garante a aprendizagem autêntica e profunda.

h) O professor deve dar as aulas sem falar.

Quanto mais o professor fala, menos aprendem os estudantes. O professor não deve dar respostas, mas fazer perguntas. As perguntas são mais importantes que as respostas. A aula deve ser uma construção heurística e hermenêutica, deve se desenvolver 
mediante um sistema de perguntas problematizadoras. Não se aprende escutando, mas perguntando, questionando tudo o que é dado, problematizando. O perguntar, o refletir sobre o perguntado e o dialogar sobre o refletido constituem a configuração triádica que garante a formação holística e o desenvolvimento humano integral. Não há aprendizagem sem conflito cognitivo. Sem dilemas e tensões intelectuais não se aprende. A contradição engendra e gera o desenvolvimento humano integral.

i) Não ensinar a partir de uma perspectiva ontológica, mas epistemológica.

Isto é, não nos referirmos a conteúdos curriculares como se estes existissem de maneira independente de quem fala (perspectiva ontológica). O lócus de enunciação é muito importante na definição dos conteúdos. Todos os conteúdos existentes na história da humanidade foram enunciados por alguém (perspectiva epistemológica).

j) Não pensar no que queremos mudar em nossos estudantes, mas no que devemos conservar.

Nenhuma ação alheia ao estudante determina seu desempenho. As estratégias didáticas têm limites, e estes limites são postos pelo estudante. Quando conservamos a configuração humana essencial e invariável, todos os demais processos mudam em torno às configurações que conservamos.

Partindo dessas reflexões, podemos afirmar que as organizações educacionais não devem educar para a aprovação em um exame acadêmico, mas para a vida. Definitivamente, o paradigma do "bom viver" (Sumak Kawsay) ou "viver bem" (Suma Qamaña) e a configuração pedagógica da felicidade baseada na pedagogia do amor (Ortiz 2014) garante uma educação para a vida, totalmente oposta à concepção desenvolvimentista imposta a partir da modernidade/colonialidade. É por isso que Walsh (2009) elabora a noção de pedagogia decolonial partindo dos princípios do bom viver, ou seja, não somente a partir de critérios teórico-críticos, mas a partir de ações práticas de insurgência educacional, o que se traduz em um processo de criação, configuração e invenção de novas condições culturais e de pensamento, de novos postulados e práticas políticas e sociais. Neste sentido, as pedagogias são as ações, estratégias, metodologias e práticas que se configuram em/por/com/a partir/para a cimarronagem, a afirmação, a insurgência, a oposição, a re-existência, a re-humanização e a resistência (Walsh, 2009).

Seguindo estas ideias, no Grupo de Estudos Decoloniais (GEDE), desenvolvemos várias propostas sobre o Fazer Decolonial:

a. Autodecolonialidade: altersofia - não epistemologia - para a configuração de um pensamento alterativo. 
b. Urgênciadeumcurrículodecolonialno/doSul:caracterizaçãodaspráticascurriculares que reproduzem uma educação colonizante nas organizações educacionais.

c. Feminismo Alterativo: uma forma "outra" de sentir, conhecer, pensar, aprender, ser e viver.

d. Interculturalidade Decolonial: urgência/emergência de saberes "outros" nos processos sociais e educacionais.

e. A decolonialidade no contexto afro-colombiano e nas obras de Gabriel García Márquez e José Martí Pérez.

f. Pensar a decolonialidade da educação, a formação e o ensino: bases epistêmicas para uma pedagogia, um currículo e uma didática decoloniais.

g. Relações e interseções entre decolonialidade, alteridade e comunalidade.

h. Três décadas decolonizando: estado da arte da pesquisa decolonial no/do Sul (1988-2018).

i. Vigência/Pertinência do pensamento alterativo no/do Sul.

j. Vocação decolonial desde as biopráxis pedagógicas.

A partir desses projetos de pesquisa realizamos várias reflexões, a partir da perspectiva do Fazer Decolonial, prática libertadora, emancipatória e decolonizante, sustentada por três ações/princípios/critérios: observação decolonial, diálogo afetivo e reflexão configurativa. A seguir, algumas perguntas para se pensar uma pedagogia decolonial:

- Como se aprende e como se ensina nas organizações educativas?

- Que orientações didáticas predominam no espaço das salas de aula das organizações educacionais?

- Como incidem as geopolíticas do conhecimento e os condicionantes institucionais na formação dos professores?

- Que traços caracterizam as práticas pedagógicas dominantes?

- Como se planeja o currículo nas organizações educacionais?

- Como os docentes selecionam os conteúdos que ensinam?

- Que conteúdos são ensinados? Quem os planejou? Quando? Para que e para quem?

- A partir de que lócus de enunciação foram planejados os conteúdos ensinados?

- De que maneira poderia ser planejar uma ciência sócio-humana "outra" e uma pedagogia "outra", que não reproduzam nem subalternizem os saberes e subjetividades, nem o ocidentalismo, eurocentrismo, colonialidade e razão "universal" das ciências hegemônicas; mas que se projete e intervenha a partir de olhares sociais e epistêmicos decoloniais? 
Os resultados parciais derivados da execução desses projetos se encaminham na direção de uma reconfiguração das ciências sociais por meio da decolonialidade da Educação. Repensar as Ciências Sociais, abri-las, configurar uma nova ciência social para o século XXI; isto é o que nos propõe Wallerstein (2007b; 2010a; 2011), que desvela os limites dos paradigmas do século XIX e desconstrói o eurocentrismo, partindo da análise do universalismo europeu, do poder do discurso através do discurso do poder (Wallerstein, 2007a). Este autor nos apresenta um diagnóstico amplo, fino e profundo do sistema mundo, oferendo um exato raio- $\mathrm{X}$ do capitalismo moderno/colonial (Wallerstein, 2010b).

Partindo desta perspectiva, estamos tentando configurar uma Pedagogia, um Currículo e uma Didática, com base nas perspectivas decoloniais. A partir daqui propomos a noção de Interculturalidade Decolonial. Urge construir um Pensamento da Decolonialidade. Por isso propomos transitar partindo da interculturalidade crítica na direção da interculturalidade decolonial configurativa.

O diálogo decolonial tem nos feito ver que o amor e a felicidade são pedagogias decoloniais úteis para o desenvolvimento do pensamento configurativo na formação holística. Reconfigurar a educação do Sul é a base para transitar na direção de uma pedagogia decolonial. Precisamos de uma epistemologia de fronteira: o Decolonialismo ou a Decolonialogia como um paradigma epistemológico "outro"; isto é, não outro paradigma superior ao paradigma dominante atualmente, mas um paradigma outro que coexista com o paradigma vigente. É necessário transitar na direção de uma metodologia de pesquisa decolonizante (Smith, 2013) sustentada por uma epistemologia decolonial.

Devemos analisar a epistemologia e a pesquisa no século XXI, seus desafios decoloniais, fazer uma crítica à razão decolonial e voltar-nos na direção de uma racionalidade decolonial. Para isso é preciso pensar a pedagogia, o currículo e a didática a partir de uma perspectiva decolonial, o que implica mover-nos da educação intercultural para a educação decolonial, renovar a educação, reinventar a pedagogia, decolonizar a formação, repensar o currículo sob um olhar decolonial, decolonizar o ensino, reinventar a didática. Devemos educar para decolonizar, construir uma pedagogia da decolonialidade. É necessário configurar o currículo e a didática com um olhar decolonial, transitar na direção de um ensino decolonial.

Aaprendizagem decolonial é um imperativo no/do bya-Yala. Devemos reconfigurar o perfil do professor decolonial, delinear as características da aula transmoderna, caracterizar as competências decoloniais, propor um modelo pedagógico decolonizante, que ressignifique o lugar do estudante decolonizado, o papel do professor decolonizante e reconfigurar a decolonialidade da epistemologia, da metodologia da pesquisa, da educação, 
da formação, do ensino, da aprendizagem, da pedagogia, do currículo, da didática. Enfim, é imperativo decolonizar a mente humana, o pensamento, a linguagem, a vida.

Como se observa atentamente, são imensos os desafios que temos. O desafio de decolonizar a pedagogia, o currículo e a didática mediante a ciência decolonial implica decolonizar a epistemologia e a metodologia da pesquisa. Devemos formular um método de pesquisa decolonialógico, que nos permita configurar o currículo decolonial, a didática decolonial; a aprendizagem decolonizante, o ensino decolonial, a avaliação decolonial. A formação no século XXI deve ser decolonizante. A decoloniagonia ${ }^{5}$ hoje nos mantêm inertes, ficamos perplexos ante a impotência de ver a colonialidade em todos os eventos e situações humanas, diluída como o sal no mar e não poder fazer nada para deter sua influência devastadora. Será que o pensamento de fronteira, enquanto pensamento de construção decolonial pode contribuir para a autodecolonialidade? Qual é o lócus de enunciação costeiro/caribenho/colombiano, que nos permite alcançar a decolonialidade holística? É possível construir uma inteligência decolonial? Como estimular a construção do pensamento decolonial nas crianças? Isto só é possível nas biopráxis pedagógicas decoloniais.

\section{BIOPRAXIS PEDAGÓGICAS DECOLONIAIS}

Como já afirmamos, Walsh (2009) concebe a pedagogia não como uma ciência nem como uma disciplina acadêmica, mas como uma política sociocultural. A construção desta noção projeta uma visão pedagógica que vai muito mais além dos processos de ensino e de aprendizagem, e ultrapassa a concepção eurocêntrica de que a pedagogia está relacionada à transmissão do saber, assumindo-a como um modo de luta coletiva, crítica e dialógica; como política de produção e transformação; e como prática social.

Walsh (2008a; 2013;2014a; 2014c; 2014d) afirma que esta perspectiva pedagógica ainda está em construção, não só do ponto de vista teórico, mas também do prático. Quando analisamos profundamente esta proposta inovadora e original, revelamos a base de sua inspiração e encontramos os principais referenciais para a sua formulação nas práticas educacionais de Freire (2012b; 2013a); e nos construtos teóricos de Fanon (2013; 2016), sobretudo aqueles relacionados à consciência do oprimido e à necessidade de humanização dos povos subalternizados. Walsh (2013) propõe a configuração entre o pedagógico e o decolonial a partir da leitura de Freire, compreendendo e assumindo que são pedagogias

\footnotetext{
${ }^{5}$ Introduzimos a noção de Decoloniagonia com duplo sentido: é a agonia pela não concretização da decolonialidad e é a visão da decolonialidade, como a vemos e assumimos desde a colonialidade que vivemos cotidianamente.
}

Revista X, v. 16, n. 1, p. 118-146, 2021. 
que delineiam caminhos não somente para ler o mundo de maneira crítica, mas também para reinventar a sociedade. Igualmente, da leitura de Fanon assume tais pedagogias como ações concretas que configuram uma nova humanidade a partir da descolonialização.

Em certas ocasiões, os governos locais, regionais e nacionais, e inclusive os diretores de organizações educacionais implementam processos de reforma educativa a nível nacional, regional ou institucional, executando ações reformistas a partir de concepções e ações algébricas, adicionando diversidade cultural às estruturas estabelecidas, mas sem realizar mudanças estruturais profundas destinadas a reconhecer e a evidenciar as diferenças como elementos constitutivos de uma pedagogia decolonial. Desta maneira, assumem-se as diferenças como diversidade cultural e não se reconhece o caráter colonial delas; ou seja, não se consideram diferenças coloniais que emergiram e se desenvolveram a partir de configurações naturalizadas e hierarquizadas, que desde a época da Colônia são imanentes à matriz política, conformando o que hoje conhecemos como colonialidade do poder. É por isso que Walsh (2013) assume as pedagogias decoloniais não como epistemes, teorias ou saberes, mas como metodologias emergentes nos contextos de marginalização, subalternização, luta, re-existência e resistência; pedagogias como práticas insurgentes de resistir, (re)existir e (re)viver, que tornam possíveis maneiras outras de estar, existir, pensar, saber, sentir, ser e viver-com. Pedagogias que rompem com a modernidade/ colonialidade a partir das biopráxis pedagógicas decoloniais.

Estas reflexões constituem uma tentativa de mostrar a recepção positiva da narrativa decolonial na Colômbia e na América Latina, não somente como teoria e discurso, mas também como epistemologia, como ação e como prática na educação. Denominamos a estas ações, eventos e acontecimentos, nos quais subjazem intencionalidades formativas de "biopráxis pedagógicas decoloniais", que surgem porque também existem práticas colonizantes. Com efeito, toda tentativa de exploração e dominação gera novos ciclos conflitivos, toda práxis colonial gera de maneira simultânea práxis decoloniais (Borsani e Quintero, 2014).

Ortiz (2017e) caracteriza a gênese do giro decolonial nas ciências da educação e valoriza a possibilidade de desenvolver biopráxis pedagógicas decoloniais. A biopráxis segundo Ortiz (2013) é uma construção teleonômica formada pelo que é momentaneamente indubitável e previamente óbvio, a certeza do fato, a convicção profunda, a convergência de distinções; a coerência da operação, a harmonia do ato, o fechamento momentâneo da circularidade autopoiética plena de sentido. A biopráxis humana é uma distinção, uma identificação que está imersa ou é imanente aos processos configurativos do ser humano, é a súbita surpresa que nos assombra, extasia e abstrai, é o que nos atravessa, o que nos 
ocorre, o que nos sucede e acontece neste preciso momento, neste instante. Neste sentido é que Ortiz (2013) afirma que o ideal da educação é a autoconstrução de cada ser humano nela envolvido como um observador. $\mathrm{O}$ ser humano se autoconstrói em seu contexto configurativo e fonte de perturbações no domínio linguístico no qual se encontra em cada momento. As características dos diversos domínios consensuais nos que cada ser humano participe, a emoção que sustenta cada um deles, têm consequências importantes no fluir ontogênico desse ser humano. "Aquele que defende um modo de vida e quer que ele se traduza e seja refletido em suas relações, deveria vivê-lo sem hesitação. Esperar não serve" (MATURANA e PÖRSKEN, 2010, p. 204); é por isso que a Pedagogia como ciência que estuda o processo da educação deve comprometer-se com as aspirações mais legítimas do ser humano e, certamente, com sua autodecolonialidade.

Nesta reflexão chamamos biopráxis pedagógicas decoloniais a todas aquelas ações críticas, desobedientes, emancipatórias, indisciplinadas, insubordinadas e insurgentes, libertadoras, obstinadas, resistentes e transformadoras, que emergem no processo formativo, seja dentro ou fora das salas de aula, seja em espaços acadêmicos e extra-acadêmicos, destinadas a diluir a decolonialidade em tais espaços com o objetivo de projetar horizontes futuros de alternativas à matriz colonizante. Agora, nossa ação decolonizante tem duas dimensões: uma teórico-epistêmica e outra praxiológica. Tentamos decolonizar a pedagogia na sua qualidade de saber, disciplina acadêmica e/ou ciência, mas também tentamos decolonizar a Pedagogia no que se refere à práxis, no dia a dia da sala de aula, em nossa ação. Como bem percebe Palermo (2014), diferentemente dos sociólogos, antropólogos, etnólogos, psicólogos e outros cientistas sociais e profissionais das humanidades, nosso trabalho de campo se concretiza na sala de aula, nos processos de ensinar, aprender e avaliar, que constituem processos e experiências construtivas, geradoras de saberes diversos, com pessoas diversas em contextos diversos. Ou seja, nossas biopráxis pedagógicas decoloniais não se desenvolvem em/com/por/ para populações indígenas nem em/com/por/para comunidades de afrodescendentes, senão na sala de aula em/com/por/para estudantes de diversas faixas etárias, diversos ritmos e estilos de aprendizagem, diversos níveis de instrução, heterogeneidade em seu desenvolvimento relativo às suas competências (conhecimentos, habilidades, destrezas), procedência diversa e, certamente, de diversas culturas, costumes, aspirações, sonhos, anseios, medos e esperanças.

As biopráxis pedagógicas decoloniais estão conformadas por ações formativas que se desenvolvem decolonialmente, isto é, desde uma perspectiva ou com um enfoque decolonial. São todas aquelas ações pedagógicas, curriculares, didáticas e/ou avaliativas 
que levam em conta "o outro"; não o subalternizam; não o levam à periferia, nem o abandonam na fronteira, mas que o aceitam na convivência formativa, em um ato que só é possível pelo amar. As biopráxis pedagógicas decoloniais se expressam, manifestam e materializam na configuração do currículo, isto é, no planejamento, desenvolvimento e/ ou avaliação; e ganham vida na didática: no ensinar, no aprender e no avaliar.

\begin{abstract}
A sala de aula é um lugar inquestionável para propiciar a abertura à contingência e aos processos institutivos de subjetivação que se articulam difusa e confusamente nele. Na medida em que conseguimos afirmar nossa tarefa docente neste terreno como um trabalho eminentemente problemático, nós mesmos somos postos em questão. E isto não só porque escolhemos percorrer os temas a partir do espaço e do tempo que nos possibilita a pergunta, mas, principalmente, porque nos arriscamos quando preferimos não legitimar nosso discurso na suposta propriedade e transmissão de "verdades indubitáveis". Escolhemos pôr em questão a nós mesmos e o mundo que representamos. E isto é uma parte substantiva da aposta. (AGUER, 2014, p.110).
\end{abstract}

Aguer (2014) nos exorta a problematizar, questionar e decolonizar nossa própria prática pedagógica, mas como se decoloniza uma prática pedagógica? Como se desenvolvem as biopráxis pedagógicas decoloniais?

Quando desenvolvemos o fazer decolonial com docentes universitários ou de instituições educacionais, evidenciamos nas narrações de suas experiências as estratégias que utilizam decolonizar suas práticas pedagógicas; e o fazem a partir da desobediência institucional, da indisciplina epistêmica e epistemológica, do questionamento ao conhecimento eurocêntrico das disciplinas, construindo espaços participativos simétricos, integrando ao currículo as tecnologias da informação e as comunicações, com o objetivo de oferecer a atualidade do mundo às instituições educacionais periféricas em um processo que se origina de um projeto glocal. "Trata-se de uma articulação entre o local e o global, algo que se retroalimenta em condições de defender o local como força política que utiliza a tecnologia global em seu benefício próprio" (PALERMO, 2014, p.108).

Resumindo, podemos afirmar que este trabalho é em si mesmo uma prática decolonizante, porque:

- Configura um espaço/encontro discursivo humanizante que ignora o discurso autoritário e o substitui pelo dialogar afetivo e o refletir construtivo que possibilita aportar conhecimento coletivo.

- Desconstrói as hierarquias entre nós, participando de maneira simétrica, ativa e dialógica na construção de epistemes "outras". 
- Desarticula nossas próprias práticas pedagógicas, convertendo-se em uma ferramenta para a decolonialidade holística organizacional.

- Potencializa a crítica e a autocrítica do nosso próprio pensamento decolonial e posicionamentofronteiriçocomobases essenciaisparadarsustentabilidadeaprojetos de longo alcance que se reproduzem em outros espaços nos quais participamos.

Finalmente, se nós queremos desenvolver as biopráxis pedagógicas decoloniais, devemos fazê-lo com a intenção de construir um pensamento decolonial e, ao mesmo tempo, estas pedagogias decoloniais exigem que desenvolvamos nosso pensamento a partir da margem e da fronteira; assim, condição sine qua non para o desenvolvimento das biopráxis pedagógicas decoloniais é precisamente o desenvolvimento de um pensamento fronteiriço e de um posicionamento sustentado na opção decolonial, é por isso que as configurações pedagógicas, curriculares e didáticas não podem ser universais, mas diversas, plurais e pluriversais.

\section{REFERÊNCIAS}

AGUER, Barbara (ed). Cartografías del Poder y descolonialidad. Del Signo: Buenos Aires. 2014.

BAUTISTA, Rafael. Bolívia: del Estado colonial al Estado Plurinacional. La Paz: Bolívia. 2009.

BOBBITT, John Franklin. How to make a curriculum. Riverside: Cambrigde, 1924.

BOBBITT, John Franklin. The curriculum of modern education. MacGraw-Hill: Nova York, 1941.

BORSANI, María Eugenia; QUINTERO, Pablo (org). Los desafios decoloniales de nuestros días: pensar en colectivo. Universidad Nacional del Comahue: Argentina, 2014.

CASTRO-GÓMEZ, Santiago. La restructuración de las ciencias sociales en América Latina. Centro Editorial Javeriano: Bogotá, 2000.

COMÊNIO, Jan Amos. Didáctica Magna. Akal: Madrid, 2012 [1630].

ESMERAL, Simón José; GONZÁLEZ, Luis Alfredo. Pedagogía e Interculturalidad. Criterios dialógicos de las realidades socioeducativas en el Caribe colombiano. Kimpres: Bogotá, 2015. 
FANON, Frantz. "Racismo y cultura", In: Por la revolución africana. Fondo de Cultura Económica: México, 1965. pp 38-52.

FANON, Frantz. Los condenados de la tierra. FCE: Buenos Aires, 2013 [1961].

FANON, Frantz. Piel negra, máscaras blancas. Akal: Madri. 2016 [1952].

FREIRE, Paulo. "Justificativa da pedagogia do oprimido", In: Pedagogia do oprimido. Paz e Terra: Rio de Janeiro, 1987 [1970].

FREIRE, Paulo. Pedagogía de la Esperanza. Un reencuentro con la Pedagogía del Oprimido. Siglo XXI: Madri, 2011 [1992].

FREIRE, Paulo. Pedagogía del Oprimido. Siglo XXI: Madri, 2012 [1970].

FREIRE, Paulo. Cartas a quien pretende enseñar. Siglo XXI: México, 2012 [1993].

FREIRE, Paulo. La educación como práctica de la libertad. Siglo XXI: México, 2013 [1969].

FREIRE, Paulo. La importancia de leer y el proceso de liberación. Siglo XXI: México, 2013 [1984].

FREIRE, Paulo. Pedagogía de la Autonomía. Saberes necesarios para la práctica educativa. Siglo XXI: México, 2014 [1996].

GONZÁLEZ, Pablo. Reestructuración de las ciencias sociales: Hacia un nuevo paradigma. Universidad Nacional Autónoma de México. Centro de Investigaciones Interdisciplinarias en Ciencias y Humanidades. Coordinación de Humanidades: México, 1998. pp. 267-285.

GRANDE, Sandy. "Red Pedagogy. The Un-methodology". In: DENZIN, Norman; LINCOLN, Yvonna; SMITH, Linda Tuhiwai (eds) Handbook of Critical and Indigenous Methodologies. Sage: London, 2008.

HERBART, Johann Friedrich. Pedagogía General derivada del fin de la educación. Ediciones de la Lectura: Madrid, 1806.

HORKHEIMER, Max. "Teoría tradicional y teoría critica”, In: Teoría critica. Amorrortu: Buenos Aires, 1998 [1937].

ILICH, Ivan. La sociedad desescolarizada. Barral: Madri, 1974. 
MALDONADO-TORRES, Nelson. "La topología del ser y la geopolítica del saber. Modernidad, imperio, colonialidad”, In: Cuaderno 1. (Des)colonialialidad del ser y del saber. Ediciones del Signo: Buenos Aires, 2006. pp. 63-130.

MALDONADO-TORRES, Nelson. Césaire's Gift and the Decolonial Turn. Radical Philosophy Review, 9 (2). Ohio, 2006. pp. 63-130.

MARTÍ, José. Ideário pedagógico. Imprenta Nacional de Cuba: Havana, 1961.

MARTÍ, José. Obras Completas, vol 18. Editorial Ciencias Sociales: Havana, 1975.

MARTÍ, José. Obras escogidas. Três volumes. Ciencias Sociales: Havana, 2007 [1978].

McLAREN, Peter. Pedagogía crítica y cultura depredadora. Políticas de oposición en la era postmoderna. Paidós: Barcelona, 1997.

McLAREN, Peter. Revolutionary Multiculturalism. Pedagogies os Dissent for the New Millennium. Boulder, Co. Westview Press: Boulder, 1997.

McLAREN, Peter. Pedagogía, identidad y poder. Homo Sapiens: Rosario, 1998.

MIGNOLO, Walter. "Epílogo: Después de América" e "Postfacio a la edición en español: 'Después de América Latina, una vez más"'. In: La idea de América Latina. La herida colonial y la opción decolonial. Gedisa: Barcelona, 2007. pp. 169-181, 201-219.

MIGNOLO, Walter. "El pensamiento decolonial. Desprendimiento y apertura. Un manifiesto". In: CASTRO-GÓMEZ, Santiago; GROSFÓGUEL, Ramón (eds): El giro decolonial. Reflexiones para una diversidad epistémica más allá del capitalismo global. Siglo del Hombre: Bogotá, 2007.

MIGNOLO, Walter. La idea de América Latina. La herida colonial y la opción decolonial. Gedisa: Barcelona, 2007.

MIGNOLO, Walter. "La opción de-colonial: desprendimiento y apertura. Un manifiesto y un caso”. Revista Tabula Rasa, no8, janeiro-julho, Bogotá, 2008. pp. 243-281.

MIGNOLO, Walter. Género y descolonialidad. Colección Pensamiento Critico y Opción Descolonial. Ediciones del Signo: Buenos Aires, 2008.

ORTIZ, Alexander. Configuralogía. Paradigma epistemológico y metodológico en las Ciencias Humanas y Sociales. Antillas: Barranquilla, 2013. 
ORTIZ, Alexander. Pedagogías del amor y la Felicidad. Ediciones de la U. Bogotá: Bogotá, 2014.

ORTIZ, Alexander. Epistemología y metodología de la investigación configuracional. Ediciones de la U. Bogotá: Bogotá, 2015.

ORTIZ, Alexander. Epistemología de la modernidad. Cambio de paradigma en el siglo XXI. Klasse: Bogotá, 2016.

ORTIZ, Alexander. Humberto Maturana. Nuevos paradigmas en el siglo XXI. Psicología, Educación y Ciencia. Klasse: Bogotá, 2016.

ORTIZ, Alexander. La ciencia del tercer milenio. Hacia un nuevo paradigma epistemológico. EDIBERUM: Bogotá, 2016.

ORTIZ, Alexander. La investigación según Humberto Maturana. El amor y la autopoiesis de investigación. Magisterio: Bogotá, 2016.

ORTIZ, Alexander. La investigación según Leonardo da Vinci. Filosofía, Epistemología y Ciencia. Magisterio: Bogotá, 2016.

ORTIZ, Alexander. La investigación según Niklas Luhmann. Epistemología de los sistemas y método sistémico de investigación. Magisterio: Bogotá, 2016.

ORTIZ, Alexander. Niklas Luhmann. Nueva teoría general de sistemas. Klasse: Bogotá, 2016.

ORTIZ, Alexander. Niklas Luhmann. Teoría emergente de los sistemas sociales. Klasse: Bogotá, 2016.

ORTIZ, Alexander. Currículo y Didáctica. Curso desarrollado en el Doctorado en Ciencias de la Educación. Universidad del Magdalena. Santa Marta. Colombia, 2017.

ORTIZ, Alexander. Decolonizar la educación. Pedagogía, Currículo y Didáctica decooniales. Klasse: Bogotá, 2017.

ORTIZ, Alexander. "Decolonizar la investigación en la educación". Revista Praxis. Universidad del Magdalena: Colômbia, 2017.

ORTIZ, Alexander. Reflexiones realizadas en las diversas reuniones para analizar los resultados de las pruebas Saber Pro 2016. Facultad de Ciencias de la Educación. Universidad del Magdalena: Colômbia, 2018. 
ORTIZ, Alexander; SALCEDO, Mileidy. Pensamiento Configuracional. REDIPED: Bogotá, 2014.

PALERMO, Zulma (org). Para una Pedagogía decolonial. Del Signo: Buenos Aires, 2014.

PALERMO, Zulma (ed). Des/decolonizar la universidad. Del Signo: Buenos Aires, 2014.

SANTOS, Boaventura de Sousa. Conocer desde el Sur. Para una cultura política emancipatoria. Editorial de la Facultad de Ciencias Sociales UMMSM: Peru, 2006.

SANTOS, Boaventura de Sousa. Renovar la teoría crítica y reinventar la emancipación social. CLACSO: Buenos Aires, 2006.

SILVA, Tomaz Tadeu da. Documentos de identidad: Introducción a las teorías del currículum. Autêntica: Belo Horizonte, 1999.

SMITH, Linda Tuniwai. A decolonizar las metodologias. Investigación y pueblos indigenas. LOM: Chile, 2013 [1999].

TYLER, Ralph: Principios básicos del currículo. Troquel: Buenos Aires, 1986 [1986].

VAZQUEZ, Rolando: "Towards a Decolonial Critique of Modernity. Buen Vivir, Relationality and the Task of Listening". In: BETANCOURT, R. Fornet (ed). Capital, Powerty, Development. Denktradi-tionen im Dialog, Vol 33. Aachen. Wissenschaftsverlag: Mainz, 2012. pp 241-252.

WALLERSTEIN, Immanuel. Utopística o las relaciones históricas del Siglo XXI. Siglo XXI: México, 2003 [1998].

WALLERSTEIN, Immanuel. Universalismo europeo. El discurso del poder. Siglo XXI: México, 2007.

WALLERSTEIN, Immanuel. Conocer el mundo, sobre el mundo: el fin de lo aprendido. Una ciencia social para el siglo XXI. Siglo XXI: México. 2007 [1999].

WALLERSTEIN, Immanuel. Impensar las ciencias sociales. Limites de los paradigmas decimonónicos. Siglo XXI: México, 2010 [1991].

WALLERSTEIN, Immanuel. Análisis de sistema mundo. Una introducción. Siglo XXI: México, 2010 [2004]. 
WALLERSTEIN, Immanuel. Abrir las ciencias sociales. Siglo XXI: México, 2011 [1996].

WALSH, Catherine. "Interculturalidad y (de)colonialidad: diferencia y nación de otro modo". In: Desarrollo e interculturalidad, imaginario y diferencia: la nación en el mundo Andino. Academia de la Latinidad: Quito, 2006. pp 27-43

WALSH, Catherine. "Interculturalidad y culturalidad del poder: Un pensamiento y posicionamiento otro desde la diferencia colonial". In: WALSH, Catherine; GARCÍA LINERA, Álvaro; MIGNOLO, Walter: Interculturalidad, descolonización del Estado y conocimiento. Serie El desprendimiento, pensamiento crítico y giro decolonial. Del Signo: Buenos Aires, 2006. pp. 21-70.

WALSH, Catherine. "Interculturalidad crítica pedagogía decolonial”. In: GRUESO BONILLA, Arturo; VILLA, Vilmer (eds): Interculturalidad, diversidad y construcción de ciudad. Alcaldía Mayor de Bogotá e Universidad Pedagógica Nacional: Quito, 2008. pp. 44-63.

WALSH, Catherine. "Interculturalidad, plurinacionalidad y decolonialidad: las insurgencias político-epistémicas de refundar el estado". Revista Tabula Rasa, n. 9, julhodezembro. Bogotá, 2008. pp. 131-152.

WALSH, Catherine. Interculturalidad, Estado, Sociedad. Luchas (de) coloniales de nuestra época. Abya-Yala: Quito, 2009.

WALSH, Catherine. Interculturalidad y (de) colonialidad. Perspectivas Críticas y políticas. Visão Global: Joaçaba, 2012.

WALSH, Catherine. La construcción del campo moderno del arte en el Ecuador, 18601925: Geopoliticas del Arte y Eurocentrismo. Tese de doutoramento em Estudos Culturais Latino-americanos. Universidad Andina Simón Bolívar: Ecuador, 2012.

WALSH, Catherine. Interculturalidad crítica y decolonialidad. Ensayos desde Abya Yala. Abya-Yala: Quito, 2012.

WALSH, Catherine: Pedagogías decoloniales. Prácticas insurgentes de resistir, (re) existir y (re)vivir. Vol. I. Abya-Yala: Quito, 2013.

WALSH, Catherine. Interculturalidad Crítica y Pedagogía Decolonial: Apuestas (des)de el In-surgir, re-existir y Re-vivir. Universidad Pedagógica Nacional-CONACIT. Plaza y Valdés Editores: México, 2014. 
WALSH, Catherine. Notas Pedagógicas desde las Grietas Decoloniales. Universidad Andina Simón Bolívar: Ecuador, 2014.

WALSH, Catherine. "Pedagogías Decoloniales. Caminando y Preguntando. Notas a Paulo Freire desde Abya Yala". Revista Entramados - Educación y Sociedad, nº 1, 2014. pp. 17-31.

WALSH, Catherine. Lo Pedagógico y lo Decolonial: Entretejiendo Caminos. Querétaro: México, 2014.

WALSH, Catherine. "Interculturalidad y colonialidad del poder. Un pensamiento y posicionamiento otro desde la diferencia colonial". In: MIGNOLO, Walter (ed). Interculturalidad, descolonización del Estado y del conocimiento. Del Signo: Buenos Aires, 2014.

WALSH, Catherine. "Decolonialidad, interculturalidad, vida desde el Abya Yala-andino: notas pedagógicas y senti-pensantes". In: BORSANI, María Eugenia; QUINTERO, Pablo (org). Los desafíos decoloniales de nuestros días: pensar en colectivo. Universidad Nacional del Comahue: Argentina, 2014. pp. 47-78.

WALSH, Catherine. Pedagogías Decoloniales. Prácticas insurgentes de resistir, (re) existir y (re)vivir. Vol. II. Abya-Yala: Quito, 2017.

WALSH, Catherine; SCHIWY, Freya; CASTRO_GÓMEZ, Santiago (ed). Indisciplinar las ciencias sociales. Geopolíticas del conocimiento y colonialidad del poder: perspectivas desde lo andino. Indisciplinar las ciencias sociales. Geopoliticas del conocimiento y colonialidad del poder: perspectivas desde lo andino. Universidad Andina Simón Bolívar\ Abya-Yala: Quito, 2002.

ZULUAGA, Olga Lucía. Pedagogía e historia. La historicidad de la pedagogía. La enseñanza, un objeto de saber. Foro Nacional por Colombia. Bogotá, 1987.

ZULUAGA, Olga Lucía. “El saber pedagógico: experiencias y conceptualizaciones”. In: Encuentrospedagógicostransculturales: desarrollocomparado delasconceptualizaciones y experiencias pedagógicas en Colombia y Alemania. Editorial Marín Vieco: Medellín, 2001. pp 81-88.

ZULUAGA, Olga Lucía. "El pasado presente de la pedagogía y la didáctica". In: ZULUAGA, Olga Lucía: et. al. El pasado presente de la pedagogía y la didáctica. Magisterio: Bogotá, 2003. 
ZULUAGA, Olga Lucía. "Foucault: una lectura desde la práctica pedagógica". In: ZULUAGA, Olga Lucía et. al. Foucault, la pedagogía y la educación. Pensar de otro modo. Magisterio: Bogotá, 2005. 